\title{
O Evangelho de Marcos: Uma análise semiótica de um Cristo carnavalizado
}

Camila Leite Oliver Carneiro ${ }^{1}$

\section{RESUMO}

Este artigo analisa a perícope de Marcos 11,1-11 sob o prisma da Semiótica Greimasiana. A abordagem da pesquisa é qualitativa, pois trabalha com o universo de significados, motivos, aspirações, crenças, valores e atitudes. No que se refere ao método, a Semiótica Greimasiana interessa-se pelo texto como um todo, e aceita o fato de o texto não ser a simples soma de frases. Dessa maneira, busca-se integrar, por meio da enunciação, a análise interna do texto, fundamental para que se reconheçam os mecanismos e regras de geração do discurso, com a análise externa do contexto histórico em que o texto está inserido. $\mathrm{O}$ artigo baseia-se também na referência do mundo carnavalizado apontado por Bakhtin, levantando figuras que, relacionadas às ancoragens de tempo e espaço, remetem à necessidade de libertação diante da situação de opressão vivida pela comunidade retratada no evangelho de Marcos.

\section{PALAVRAS-CHAVE}

Semiótica. Marcos. Carnavalização.

\footnotetext{
1 Mestra em Estudos de Linguagens - Docente da Universidade do Estado da Bahia. clcarneiro@uneb.br
} 


\begin{abstract}
This paper analyzes the periscope of Mark 11,1-11 from the perspective of Greimas's Semiotics. It is a qualitative research because it deals with the universe of meanings, motives, aspirations, beliefs, values and attitudes. As method, Greimas's Semiotics is interested in the text as a whole, and accept the fact that it isn't the simple sum of sentences. In this way, the paper seeks to integrate through enunciation the internal analysis, which is fundamental to recognize the mechanis$\mathrm{ms}$ and rules of generation of speech, with the external analysis of the historical context in which the text is inserted. The paper is also based on the world reference of carnival pointed out by Bakhtin, raising figures relating to anchorages of time and space, refer to the need to release before the oppressive situation experienced by the community portrayed in the Gospel of Mark.
\end{abstract}

\title{
KEYWORDS
}

Semiotics. Mark. Carnivalization.

\section{Introdução}

Ao trabalhar um texto bíblico sob o prisma da Semiótica Greimasiana e sob os olhares da teoria da carnavalização bakhtiniana, é válido ressaltar que reconhecemos esse texto como um texto literário, como o faz Magalhães já na introdução do seu livro "Deus no Espelho das Palavras":

Em primeiro lugar, destaco a relação, que qualifico de intrínseca, existente entre teologia e literatura. O cristianismo é uma religião do livro. [...] Declarar o cristianismo como uma religião do livro é afirmar que boa parte de seu poder reside no fato de ser literatura. [...] Justamente por ser literatura é que o cristianismo deverá ao lado do livro, sempre incluir a questão da memória e da narrativa ${ }^{2}$.

2 MAGAlHÃES, Antonio. Deus no Espelho das Palavras: teologia e literatura em diálogo. São Paulo: Paulinas, 2000, p. 5-8. 
E, pensando em memória ${ }^{3}$ e narrativa ${ }^{4}$ é que pensamos a Semiótica Greimasiana, também conhecida como Semiótica da Narrativa ou Semiótica Discursiva. Isto, pois o projeto da Semiótica Greimasiana é o de uma semiótica narrativa do discurso. Greimas segue a linha dos princípios da análise estrutural, tendo como fontes o estruturalismo linguístico de Hjelmslev, a antropologia estrutural de Lévi-Strauss, a teoria formalista do conto de Propp e a teoria das situações dramáticas de Etienne Souriau. Dessa maneira, é uma "teoria da significação", que apenas se torna possível quando a sua análise é situada em níveis tanto acima como abaixo dos signos. Assim,

O sentido não está por detrás do texto: ele é o sistema de regras que permite gerar o jogo diferencial das oposições, que ordena minha leitura ao longo de um texto "infinito", do qual o texto que leio nada mais é do que uma atualização limitada acidentalmente, isto é, historicamente limitada. Vale dizer que será impossível suspender a referência dos significantes e, daí, também a dos significados. Assim, se vê substituída a ilusão "suturadora" de um significado último ("os acontecimentos fundadores", para o Antigo Testamento, assinalados por Ricoeur - X, p. 611 -, ou mesmo Deus) pela enumeração da ordem produtora dessa referência ${ }^{5}$.

3 [...] memória tem relação com o fluxo temporal interior. Ela tanto é um registro do presente para conservá-lo na lembrança quanto do passado para presentificá-lo ou atualizá-lo. CARNEIRO, Everton Nery. Tempo, Memória e Narrativa: Uma caminhada docente. In: Anais do II Colóquio Docência e diversidade na Educação Básica: Políticas, práticas e formação 19-21/05/2015, ISSN 2358-0151.

4 1. O termo narrativa é utilizado para designar o discurso narrativo de caráter figurativo (que comporta personagens que realizam ações). [...] 2. Diante da diversidade das formas narrativas, foi possível perguntar-se quanto à possibilidade de definir narrativa simples. [...] analisável como a passagem de um estado anterior (que precede a absorção) a um estado ulterior (que se segue à absorção), operado com a ajuda de um fazer (ou de um processo). Nessa perspectiva, a narrativa simples se aproxima do conceito de programa narrativo. 3. No nível das estruturas discursivas, o termo narrativa designa a unidade discursiva, situada na dimensão pragmática, de caráter figurativo, obtida pelo procedimento de debreagem enunciva. Cf. GREIMAS, A. J. e COURTÉS, J. Dicionário de Semiótica. São Paulo: Contexto, 2008, p. 327.

5 CHABRAL, C. e MARIN, L. Semiótica Narrativa dos Textos Bíblicos. Rio de Janeiro: Forense-Universitária, 1980, p. 4. 
A semiótica explica os sentidos de texto e, também, os mecanismos e procedimentos que constroem os seus sentidos. Tem por objetivo o próprio texto, e não a palavra ou frase somente. Portanto, a teoria semiótica propõe-se a examinar os mecanismos e procedimentos de seu plano de conteúdo, que é concebido, metodologicamente, sob a forma de um percurso gerativo.

O percurso gerativo parte do mais simples e abstrato ao mais complexo e concreto. São estabelecidas três etapas no percurso: A primeira etapa do percurso é o nível fundamental e, nessa etapa, a significação se apresenta como oposição semântica; a segunda etapa, o nível narrativo, estrutura-se segundo a ótica de um sujeito; e a terceira, a mais complexa e concreta, é a discursiva, que se utiliza dos procedimentos de temporalização e figurativização.

Dessa forma, estuda-se o percurso gerativo aplicando-o ao texto bíblico da perícope de Marcos 11,1-11 ${ }^{6}$, observando as figuras que, relacionadas às ancoragens de tempo e espaço, remetem à necessidade de libertação diante da situação de opressão vivida pela comunidade retratada em Marcos. Percebemos, assim, que a prática libertadora do Messias vai de encontro às práticas dos poderes estabelecidos, pois ele anuncia-nos um novo reino, um reino de igualdade e justiça.

Ao entrar em Jerusalém montado em um jumento, o Messias repete carnavalizando a entrada do imperador na cidade. Este rei carnavalizado concretiza sua ideologia social, busca a negação da realidade de opressão (política, social, econômica e religiosa) a partir da simplicidade festiva com que passa o seu cortejo, como um convite à desrepressão. Este cortejo não é um simples espetáculo para manifestação do poder vigente, como seria a entrada de um imperador, é a festa do povo, com o povo e para o povo. Como afirma Bakhtin ${ }^{7}$ :

E é verdade que as formas do espetáculo teatral na Idade Média se aproximavam na essência dos carnavais populares, dos quais constituíam até certo ponto uma parte. No entanto, o núcleo dessa cultura,

\footnotetext{
6 Bíblia de Jerusalém. Nova Edição Revista e Ampliada. São Paulo: Paulus, 2002.

7 BAKHTIN, Mikhail Mikhailovitch. A cultura popular na Idade Média e no Renascimento. O contexto de François Rabelais. Tradução de Yara Frateschi Vieira. São Paulo/Brasília: Hucitec/Editora Universidade de Brasília, 2008, p. 4.
} 
isto é, o carnaval, não é de maneira alguma a forma puramente artística do espetáculo teatral e, de forma geral, não entra no domínio da arte. Ele se situa na fronteira entre a arte e a vida. Na realidade, é a própria vida apresentada com os elementos característicos da representação.

$\mathrm{Na}$ verdade, o carnaval ignora toda distinção entre atores e espectadores. Também ignora o palco, mesmo na sua forma embrionária. Pois o palco teria destruído o carnaval (e inversamente, a destruição do palco teria destruído o espetáculo teatral). Os espectadores não assistem ao carnaval, eles o vivem, uma vez que o carnaval pela sua própria natureza existe para todo o povo.

O carnaval transcende o tempo, leva-nos a uma outra realidade, ao lugar da utopia, onde a vida é plena e livre. Na passagem do cortejo do Messias, o povo celebra, vive-se o momento do extraordinário, em que o tempo é suprimido e o que prevalece é o espaço utópico: a alegria carnavalesca, a harmonização da desigualdade e da comunhão universal. Enquanto esse cortejo passa não se conhece outra vida senão a do carnaval, só se pode viver de acordo com as suas leis, ou seja, as leis da liberdade. Há o renascimento e a renovação do mundo e cada indivíduo participa deste momento. Enfim, enquanto o reino do Messias durar é a própria vida que representa e interpreta outra forma livre da sua realização, o povo penetra temporariamente no reino utópico da universalidade, liberdade, igualdade e abundância ${ }^{8}$.

Celebra-se o futuro, as alternâncias e renovações. É o tempo da abolição das relações hierárquicas, tempo em que todos são iguais, em que reina um contato livre e familiar entre todos aqueles que se encontram separados na vida cotidiana, seja pelas barreiras sociais, econômicas, de sexo, de idade ou situação familiar. Uma movimentação inconcebível em situações normais, pois esse momento de coletividade e de relações verdadeiramente humanas só é possível na proposta de reino anunciada pelo Messias e já evidente desde o primeiro versículo do Evangelho de Marcos. Porém, vale ressaltar que, ao tratar o carnaval, não estamos apenas falando da festa, mas de um tempo-espaço em que a comunidade libertase de todas as suas opressões, dos seus lugares sociais, dos seus medos.

8 OLIVER, Camila. Chico Buarque: O tempo, os temas e as figuras. Curitiba: Appris, 2013, p. 155. 
Este caráter utópico e universalizador, o qual é devido à dualidade na percepção do mundo e da vida humana, é uma das principais características do conceito de carnavalização em Bakhtin.

\section{Um Rei e um Messias: oposições}

Na perícope de Marcos, a categoria semântica fundamental é Rei/ Imperador versus Messias/Servo. Entendendo que "categoria tímica é a categoria primitiva que considera o ser vivo como um sistema de atrações e repulsões e, assim, procura formular como todo ser vivo, em um dado contexto, sente-se e reage ao seu meio", o termo Messias/Servo é tido como eufórico (termo positivo da categoria tímica) e o termo Rei/ Imperador como disfórico (termo negativo da categoria tímica). Assim, o Messias/Servo (a proposta de um reino libertador, de igualdade e justiça) é atraente, enquanto o Rei/Imperador (realidade de opressão política, econômica e social) é repulsivo.

A teoria semiótica de Greimas parte de sua definição de estrutura como diferença, princípios de oposições binárias e pertinência, e prioriza a relação entre elementos e relações de oposição: o mundo estruturado na forma de diferenças e oposições. No nível das estruturas fundamentais, é preciso determinar a oposição ou oposições semânticas, a partir das quais se constrói o sentido do texto dessa forma,

[...] Para conhecer, é necessário primeiramente negar. [...] A negação é a primeira operação pela qual o sujeito funda-se como sujeito operador e funda o mundo como cognoscível. [...] Com efeito, o mundo como valor oferecia-se inteiro ao sentir do sujeito tensivo; mas para conhecê-lo é preciso parar o desfile contínuo, isto é, generalizar o "encerramento" - essa é, pois, a fonte da primeira negação -, cercar uma zona, somar um lugar, ou seja, negar o que não é esse lugar. [...] Sem a contradição, a somação determinaria apenas uma pura singularidade no contínuo tensivo e fracassaria em fazer advir a significação[... $]^{10}$.

9 OLIVER, 2013, p 109.

${ }^{10}$ GREIMAS, Algirdas Julien e FONTANILLE, Jacques. Semiótica das paixões. Editora Ática, 1993, p. 38-39. 
Ao negar as características de rei opressor, reafirma-se em Jesus o seu reinado messiânico, libertador. O percurso que segue reflete as operações de negação e afirmação no texto:

(afirmação)
Rei
$($ disforia $)$$\rightarrow \begin{gathered}\text { (negação) } \\ \text { não-Rei } \\ \text { (não-disforia) }\end{gathered} \rightarrow \begin{gathered}\text { (afirmação) } \\ \text { Messias } \\ \text { (euforia) }\end{gathered}$

As operações sintáticas fundamentais são de negação e asserção. A negação produz termos contraditórios, enquanto a asserção reúne os termos situados no eixo dos contrários e dos subcontrários ${ }^{11}$. A análise efetuada do nível fundamental de Marcos 11,1-11 pode ser visualizada no modelo abaixo do quadro semiótico:

$\begin{array}{ll}\text { Rei/Imperador } & \text { Messias/Servo } \\ \text { Disforia } & \text { Euforia }\end{array}$
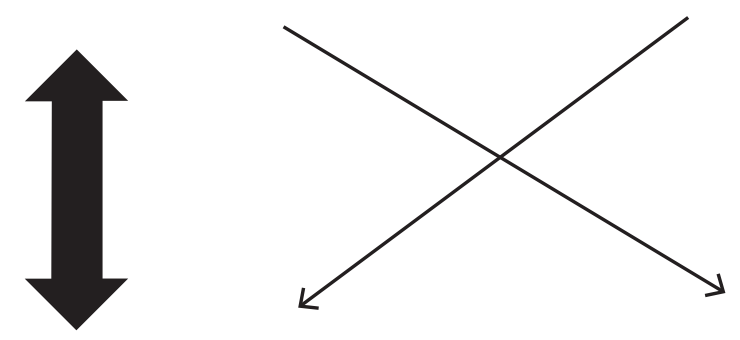

Não-Messias

Não-Euforia

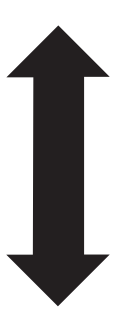

Não-Rei

Não-Disforia

termos contrários

operações de negação

termos complementares

Percebamos essas oposições no texto:

\begin{tabular}{|l|l|}
\hline REI/IMPERADOR & MESSIAS/SERVO \\
\hline Jerusalém, Betfagé, Betânia & Jumentinho que ninguém ainda montou \\
\hline Vestimentas e ramos estendidos & Hosana \\
\hline Bendito o Reino que vem, do nosso pai Davi & Entrou no templo, em Jerusalém. \\
\hline
\end{tabular}

${ }^{11}$ OLIVER, 2013, p. 104. 
Observemos que Jesus e os seus seguidores aproximam-se "de Jerusalém, diante Betfagé e de Betânia, perto do monte das oliveiras" (Mar$\cos 11,1)$. Estão a aproximar-se dos portões da cidade de Jerusalém. Um rei atravessa os portões da sua cidade em um belo cavalo com todos os paramentos, protegido por uma gigantesca tropa e reverenciado pelo seu povo, o que costumamos chamar de "entrada triunfal". É este rei que muitos que clamam a Jesus esperavam, o rei que veio para tirá-los da pobreza $^{12}$, da opressão, instaurar na terra um novo reino. $O$ rei da geração de Davi: "Bendito o Reino que vem, do nosso pai Davi! (Marcos 11,10)":

Vindo em nome de IHVH, e descendendo da dinastia de Davi, Iéshoua' é, portanto, o herdeiro legítimo do reino da Judéia. Através de sua aclamação, a multidão afirma-lhe que, sendo herdeiro de David e o messias, filho de Elohîms, deve, sem desferir um único golpe, tornar-se rei da judéia e eliminar o imperador Tibério, que é então soberano $^{13}$.

Porém, o rei que atravessa os portões de Jerusalém está montando um jumentinho emprestado, algo tão cotidiano na vida dos hebreus. Um jumentinho sem paramento algum, já que nunca havia sido usado por outrem. E, mesmo assim, alguns o reconhecem, integram-se ao seu cortejo e estendem os seus ramos e as suas vestes honrando-o, demonstrando o quanto era esperado. E clamam: "Hosana!". Sim, clamam, não louvam, pois, como nos lembra Chouraqui ${ }^{14}$ :

Hosha'na (Hosana): Esta exclamação hebraica aparece 6 vezes nos evangelhos; não é um grito de louvor, mas um pedido de socorro: "Salva, então!" (2 Samuel 14,4; 2 Reis 6,26). Entrando em Ieroushalaîms (Jerusalém), Iéshoua' é acolhido como rei enviado do céu para salvar seu povo, que está em aflição.

Observamos então neste momento o reconhecimento da característica messiânica de Jesus.

\footnotetext{
${ }^{12}$ Betânia - Béit-Hananyah - significa casa da pobreza.

${ }^{13}$ CHOURAQUI, André. A Bíblia: Marcos (O Evangelho Segundo Marcos). Trad. Leila Duarte. Rio de Janeiro: Imago, 1996, p. 172.

${ }^{14}$ CHOURAQUI, 1996, p. 172.
} 
[...] A dimensão régia da identidade messiânica de Jesus é qualificada pelas identificações anteriores derivadas da citação sincrética. Este é um rei que efetivamente governa como libertador dos pobres, e não como conquistador das nações, o que é demonstrado no evangelho pelas ações de Jesus, mas também pela interpretação dessas ações em Marcos 10,35-45. A tradição davídica da corte é retomada aqui e deslocada em seu significado, com uma radical inversão - que já pode ser vista parcialmente em Isaías 40-55 que, em certo sentido, democratiza a eleição de Davi (cf. Isaías 55,5) - a qual pode apontar para a preferência da comunidade marcana pelo davidismo popular (cf. Miquéias 5,1-4 etc) ${ }^{15}$.

É então um texto de proposta euforizante. Diz-se proposta euforizante, porque o estado de relaxamento só ocorrerá com o reconhecimento da chegada de um Messias libertador, que mesmo existindo enquanto potência naquele rei carnavalizado que adentra os portões de Jerusalém, até o final da perícope não se realiza por completo (nessa perícope, Jesus não faz nenhuma demonstração - milagres, curas - de que é o Messias), é ainda apenas ameaça. Durante todo o percurso, a comunidade encontra-se em espera amargurada (ela clama - Marcos 11,9), pois quer ser livre, não crer ser livre e sabe não poder ser livre enquanto o Messias, que a tornará competente para isso, não chegar. É por esse motivo que essa comunidade amargurada deseja o rei que viria empoderá-la.

Ainda assim, a ideia do Messias é muito mais atraente à comunidade marcana do que a ideia do rei opressor que veio transformar os oprimidos em novos opressores. A ideia do Messias é contraditória a de um rei todo poderoso que governaria para o povo. É a ideia de um rei que anuncia um reino libertador, um rei do povo, governando com o povo, caminhando com o povo. É por esse motivo que o Messias entra em Jerusalém e segue para o templo no centro da cidade como qualquer outro hebreu assim o faria e, ao fazer isso, lança seus olhos em redor, observa a suntuosidade do Templo de Herodes e continua a caminhar com a multidão.

15 ZABATIERO, Júlio Paulo Tavares. LEONEL, João. Bíblia, Literatura e Linguagem. São Paulo: Paulus, 2011, p. 196. 


\section{A narrativa}

Na Semiótica Greimasiana, na passagem do nível fundamental para o nível narrativo, as operações da sintaxe fundamental transformam-se em enunciados do fazer que regem enunciados de estado, devido ao sujeito do fazer. A narrativa se configura pela mudança de estados operada pelo fazer transformador de um sujeito que age no e sobre o mundo em busca de valores investidos nos objetos; sucessão de estabelecimentos e de rupturas de contratos entre um destinador e um destinatário, de que decorrem a comunicação e os conflitos entre sujeitos e a circulação de objetos. Ou seja, deve ser entendida como um espetáculo ${ }^{16}$, um simulacro $^{17}$ do fazer do homem que transforma o mundo.

No simulacro do rei messiânico de Marcos, a comunidade vive relações não hierárquicas, libertando-se dos seus lugares sociais, dos seus medos, das suas tristezas. Produz uma linguagem carnavalesca típica impregnada da alternância e da renovação, da consciência da alegre relatividade das verdades e autoridades no poder.

A comunidade marcana investe no objeto-valor messias os valores da liberdade, desrepressão, igualdade. Antes da chegada do Messias, a comunidade encontrava-se em disjunção com estes valores. Maria Antonia Marques descreve:

No século I, a dominação romana com seus impostos abusivos e o sistema religioso de Jerusalém tornaram-se insustentáveis. A realidade ia de mal a pior. Na Palestina, a repressão das autoridades contra as revoltas populares era violenta, um verdadeiro massacre, muitos grupos de judeus foram dizimados. A população foi deixada à sua sorte. Nesse contexto, renasceu o nacionalismo judaico: a espera de

${ }^{16}$ Espetáculo - vem dos verbos latinos specio - ver, olhar, perceber e observar. especto - examinar, ver com reflexão, provar, ajuizar, esperar. Espetáculo - pertence ao campo da visão. Cf. CHAUÍ, Marilena. Simulacro e Poder: Uma análise da mídia. São Paulo: Fundação Perseu Abramo, 2006, p.14.

17 Um simulacro é um objeto do imaginário, sem fundamento intersubjetivo, mas que determina relações intersubjetivas. "[...]fazer cognitivo contratual do sujeito do estado é denominado construção de simulacros [...]”. Cf. GREIMAS, Algirdas Julien. "De La colére. Étude de sémantique lexicale". Documents, Paris, Groupe de recherchessémio-linguistiques, 1981, p. 99. 
um messias rei. Para orientar a comunidade cristã, que também estava assumindo essa mentalidade, a liderança que escreveu o evangelho de Marcos sentiu a necessidade de apresentar Jesus como o Messias-servo, que foi crucificado por ter assumido a causa da justiça até o fim, mas Deus o ressuscitou ${ }^{18}$.

Assim, enquanto os abusos do poder geram em alguns a espera angustiada por um messias rei que viria transformar oprimidos em opressores, a comunidade marcana anuncia um messias que propõe um reino de serviço:

Sabeis que aqueles que vemos governar as nações as dominam, e os seus grandes as tiranizam. Entre vós não será assim: ao contrário, aquele que dentre vós quiser grande, seja o vosso servidor, e aquele que quiser ser o primeiro dentre vós, seja o servo de todos. Pois o filho do Homem não veio para ser servido, mas, para servir e dar a sua vida em resgate por muitos (Marcos 10,42-45).

É o reinado do povo no mundo carnavalizado bakhtiniano, que "caracteriza-se, principalmente, pela lógica original das coisas "ao avesso", "ao contrário", um empoderamento não opressor, um poder que está em servir, em irmanar-se.

No nível narrativo da Semiótica Greimasiana, analisa-se também a manipulação, "um sujeito age sobre o outro para levá-lo a querer e/ou dever fazer alguma coisa"19. Uma das manipulações se dá por meio da sedução, "o manipulador leva a fazer manifestando um juízo positivo sobre a competência do manipulado" ${ }^{20}$. Jesus, ao repetir o espetáculo do rei ao entrar na cidade, está sobre um jumentinho emprestado e sem elementos suntuosos de montaria, mostrando-se próximo ao povo, apontando para a possibilidade de construção de um reino em coletividade. Ele não era diferente de ninguém, todos podiam fazer parte desse reino, ao passo que a multidão o tentava, ou seja, mostrava que poderiam dar

\footnotetext{
${ }_{18}$ MARQUES, Maria Antonia. O Caminho de Jesus: Uma leitura do evangelho de Marcos. In: Vida Pastoral. Setembro - Outubro 2012, ano 53, n. 286, p. 3.

${ }_{19}$ FIORIN, José L. Elementos de análise do discurso. São Paulo: contexto, 1997, p. 22.

${ }^{20}$ FIORIM, 1997, p. 20.
} 
ao messias algo de positivo, estendiam vestes e ramos pelo caminho e o seguiam clamando, ou seja, davam ao Messias o reconhecimento de que era o Filho do Homem. Lembremos de que para ocorrer a manipulação, o sujeito manipulado precisa aceitar o contrato com o sujeito manipulador, um contrato fiducitário, de crença. Nesse sentido, Jesus e a multidão precisavam crer nessa proposta de reino do serviço.

Nesse nível, é preciso também compreender que o programa de ação depende da competência. "Na fase da competência, o sujeito que vai realizar a transformação central da narrativa é dotado de um saber e/ ou poder fazer" 21 . Na perícope em análise, as competências são doadas. Ao enviar os discípulos na busca pelo jumentinho, Jesus os dota de um poder fazer, lembrando-os de que tudo podem fazer em nome do Senhor: “E se alguém vos disser, 'Por que fazeis isto?', dizei: 'O Senhor precisa dele, e logo o mandará de volta"” (Marcos 11,3). Ao caminhar no meio da multidão, Jesus dota o povo de um saber e poder fazer parte da proposta libertadora de reino dos céus; bem como a multidão e os discípulos, ao reconhece-lo e segui-lo, dotam a Jesus de um poder e saber ser o messias servo libertador.

Performance é o percurso de transformação de estados. Nesse sentido, ao reconhecer e seguir o messias, o povo inicia o seu processo de conjunção com a libertação da realidade opressora, ao passo que o messias e os discípulos caminham a anunciar este reino libertador.

O percurso da sanção "é o encadeamento lógico de programas narrativos, um responsável pela sanção cognitiva (reconhecimento do "herói" e desmascaramento do "vilão"), e o outro responsável pela sanção pragmática (recompensa ou punição)" ${ }^{22}$. Nesta perícope, não temos a conclusão de toda a performance do Messias, portanto, não temos aqui revelada a sua sanção. Todavia, o final do evangelho nos aponta que, ao mesmo tempo em que alguns (os que sofrem) o reconhecem como "herói”, a sua prática libertadora está em conflito com os poderes do mundo, por esse motivo, recebe uma punição (assim vista pelo poder opressor), é condenado e morto como subversivo. Porém, a morte carnavalesca traz a ideia de satisfação, pois, “onde há morte, há ao mesmo tempo nascimen-

\footnotetext{
${ }^{21}$ FIORIM, 1997, p. 23.

${ }^{22}$ OLIVER, 2013, p. 127.
} 
to, alternância, renovação"23. Portanto, o Messias ressuscita e reacende naqueles que com ele aceitaram caminhar a esperança de um reino livre das amarras do poder opressor, pois "ao esperar com confiança, o sujeito espera por um tempo já presente em sua potencialidade e, portanto, por uma mudança já existente na própria espera" 24 .

\section{Um jumentinho: figura de um novo reino}

Passando ao nível discursivo, analisa-se, num primeiro momento, o aspecto semântico: os temas ${ }^{25}$ e as figuras ${ }^{26}$. Na perícope de Marcos 11,1-11, o tema é a afirmação da característica messiânica/serva de Jesus em detrimento do rei nos modelos do poder vigente. O jumentinho é a figura que recobre esse tema. É esse animal utilizado como meio de transporte do hebreu comum que permite ao messias anunciar um reino diferente. É o jumentinho ainda não usado, ainda não amansado, sem arreio, forrado com as vestes dos discípulos que adentra aclamado aos portões de Jerusalém. É este jumentinho que aponta firmemente para o rebaixamento das figuras poder:

Em cada indivíduo surrado e injuriado, Rabelais discerne o rei, um ex-rei ou um pretendente ao trono. Ao mesmo tempo, as figuras de todos os destronados são perfeitamente reais e vivas, como o são todos esses chicaneiros, esses sinistros hipócritas e caluniadores que ele golpeia, expulsa e injuria. Todas essas personagens são escarnecidas, injuriadas e espancadas porque representam individualmente o poder e a verdade moribundos: as ideias, o direito, a fé, as virtudes dominantes ${ }^{27}$.

${ }_{23}$ BAKHTIN, [1965] 2008, p. 358-359.

${ }^{24}$ OLIVER, 2013, p. 165.

25 "Podem se revestir os esquemas narrativos abstratos com temas e produzir um discurso não figurativo ou podem-se, depois de recobrir os elementos narrativos com temas, concretizá-los ainda mais, revestindo-os com figuras". Cf. FIORIN, 1997, p. 64 .

26 "[...] a oposição entre tema e figura remete, em princípio, à oposição entre abstrato/ concreto". Cf. FIORIN, 1997, p. 65.

${ }^{27}$ BAKHTIN, [1965] 2008, p. 184. 
A imagem do jumentinho aclamado pela multidão é a imagem do mundo carnavalizado como portadora da possibilidade de inversões dos lugares de poder, pois, tal como Bakhtin descreve no contexto de Rabelais, durante a festa, o texto da comunidade marcana apresenta o povo que domina as ruas e instaura uma forma outra de governo, com reis que serão destronados, surrados, injuriados por cada ação de serviço libertador (milagres, curas, acolhimento, partilha, ressurreição) do Messias e seus seguidores.

O Messias que atravessa os portões da cidade sobre esse jumento figurativiza a existência de um novo reino, pois "a alegre negação da identidade e do sentido único [...] expressão das transferências, das metamorfoses, das violações das fronteiras naturais [...] cria uma atmosfera especial, como se pertencesse a outro mundo"28.

A figura do cortejo que estende ramos e vestes pelo caminho apresenta-nos a instância da festa. Uma festa coletiva, sem hierarquias ou diferenças. Uma festa que não está para ser apenas assistida, na qual todos participam ativamente, vivem, pois é impossível escapar desse cortejo de renascimento e renovação. Ele figurativiza também o poder a desvanecer, ridicularizado e rebaixado.

Por isso, a possibilidade de um Messias libertador causa tensão naqueles que detém o poder em um cotidiano hierárquico, apresentandonos um percurso passional:

Ora, um fato perturbador surgiu de imediato: não apenas o sujeito do discurso é suscetível de transformar-se em sujeito apaixonado, perturbando seu dizer cognitiva e pragmaticamente programado, mas também o sujeito do "dito" discursivo é capaz de interromper e desviar sua própria racionalidade narrativa para emprestar um percurso passional, ou mesmo acompanhar o precedente, perturbando-o por suas pulsações discordantes ${ }^{29}$.

Isto porque não existe vida do povo sem as relações livres e familiares que se estabelecem na praça pública. A consciência do poder fazer (liberdade) é salutar para a interrupção do poder oficial, com suas interdições e

\footnotetext{
${ }^{28}$ BAKHTIN, [1965] 2008, p.35.

${ }^{29}$ GREIMAS e FONTANILLE, 1993, p. 17.
} 
barreiras hierárquicas. É imperativo para que a vida adentre ao domínio da liberdade utópica.

Para isso, a liderança que escreve a narrativa marcana ${ }^{30}$ utiliza o tempo pretérito de um ele - lá - outrora, observado nos verbos: "enviou", "foram", "acharam", "encontravam", "disseram", "responderam", "deixaram", "levaram", “montou”, “estenderam”, “clamavam”. Dessa forma, entendemos que a essa narrativa faz relação com o momento social, político, econômico e religioso em que foi escrita, período de grande repressão.

É possível perceber a desembreagem interna quando se dá a voz internamente, em primeira pessoa, como no exemplo nos versículos: 2, 3, 5,9 e 10 da perícope em análise. A desembreagem interna também pode ser chamada de $2^{\circ}$ grau, criando simulacros de diálogos no texto, dando voz aos atores do texto.

É um texto sem grande extensão temporal e, portanto, intenso, já que a narrativa acontece em apenas um recorte de tempo, sem que o sujeito realize grandes movimentações dentro do seu percurso. A única performance do sujeito (Messias) é atravessar os portões de Jerusalém até o templo. Sobre isso Fontanille e Ziberberg ${ }^{31}$ discorrem: "O momento da emoção reduz a duração da narrativa a um "ponto", e reorganiza o conjunto do percurso em torno do centro dêitico e sensível."

Percebe-se que a duração da narrativa foi reduzida a um ponto: o momento da entrada do Messias em Jerusalém. E o conjunto do percurso dá-se em torno desse centro dêitico e sensível: o anuncio de um reino diferente. É a história de toda uma espera vivida em um instante, o momento em que o povo une-se, nas ruas, em um misto de celebração e clamor ao Messias. Não é, então, uma história desdobrada e relatada num espaço-tempo narrativo.

${ }^{30} \mathrm{O}$ evangelho de Marcos é uma obra anônima, não existe apresentação do sujeito que fala nem sequer dos objetivos desse escrito, que somente serão descobertos na própria leitura. Cf. MARQUES, 2012, p. 4.

31 FONTANILLE, Jacquese ZILBERBERG, Claude. Tensão e significação. Tradução de Ivã Carlos Lopes, Luiz Tatit e Waldir Beividas. São Paulo: Discurso Editorial/ Humanitas/FFLCH/USP, 2001, p. 287. 


\section{Conclusão}

O fator ideológico está presente em todos os discursos e, dessa forma, ele deixa marcas que demonstram a formação social/discursiva do texto. Nesse sentido, na perícope de Marcos 11,1-11 há valores ideológicos do momento histórico-político-econômico-religioso relatado no Evangelho de Marcos. A análise do texto à luz da Teoria Semiótica de Greimas forneceu inúmeras categorias semânticas, as quais possibilitaram verificar que os discursos aí perceptíveis dialogam com outros discursos. Os traços semânticos que foram percebidos pelos temas e pelas figuras permitiram uma leitura dos temas da liberdade, inversão do poder, anúncio de um novo reino, figurativizados pelo jumento, Messias que monta o jumento, cortejo. A percepção dos vários discursos subjacentes ao texto não seria possível numa leitura tradicional, atentando apenas para a ordem linguística do texto, tratando-o como código apenas. Isso porque é um texto pluri-isotópico, no qual as várias isotopias do seu discurso são facilmente rompidas ao se identificar os seus conectores de isotopia e explorar a polissemia natural das palavras, tal qual foi realizado no momento da análise da perícope e na relação com o mundo carnavalizado bakhtiniano.

\section{Referências}

BAKHTIN, Mikhail Mikhailovitch. A cultura popular na Idade Média e no Renascimento. O contexto de François Rabelais. Tradução de Yara Frateschi Vieira. São Paulo/Brasília: Hucitec/Editora Universidade de Brasília, [1965] 2008.

Bíblia de Jerusalém. Nova Edição Revista e Ampliada. São Paulo: Paulus, 2002.

CARNEIRO, Everton Nery. Tempo, Memória e Narrativa: Uma caminhada docente. In: Anais do II Colóquio Docência e diversidade na Educação Básica: Políticas, práticas e formação. 19-21/05/2015, ISSN 2358-0151

CHABRAL, C. e MARIN, L. Semiótica Narrativa dos Textos Bíblicos. Rio de Janeiro: Forense-Universitária, 1980. 
CHAUÍ, Marilena. Simulacro e Poder: Uma análise da mídia. São Paulo: Fundação Perseu Abramo, 2006.

CHOURAQUI, André. A Bíblia: Marcos (O Evangelho Segundo Marcos). Trad. Leila Duarte. Rio de Janeiro: Imago, 1996.

FIORIN, José L. Elementos de análise do discurso. São Paulo: Contexto, 1997.

FONTANILLE, Jacques e ZILBERBERG, Claude. Tensão e significação. Tradução de Ivã Carlos Lopes, Luiz Tatit e Waldir Beividas. São Paulo: Discurso Editorial/Humanitas/FFLCH/USP, 2001.

GREIMAS, A. J. e COURTÉS, J. Dicionário de Semiótica. São Paulo: Contexto, 2008.

GREIMAS, Algirdas Julien e FONTANILLE, Jacques. Semiótica das paixões. Editora Ática, 1993.

. "De La colére. Étude de sémantiquelexicale". Documents.

Paris, Groupe de recherches sémio-linguistiques, 1981.

MAGALHÃES, Antonio. Deus no Espelho das Palavras: teologia e literatura em diálogo. São Paulo: Paulinas, 2000.

MARQUES, Maria Antonia. O Caminho de Jesus: Uma leitura do evangelho de Marcos. In: Vida Pastoral - setembro - outubro 2012 - ano 53 - n. 286, p. 3.

OLIVER, Camila. Chico Buarque: O tempo, os temas e as figuras. Curitiba: Appris, 2013.

ZABATIERO, Júlio Paulo Tavares. LEONEL, João. Bíblia, Literatura e Linguagem. São Paulo: Paulus, 2011.

Submetido em: 26/09/2015 Aceito em: 30/10/2015 